\title{
Accessory Incompatible
}

National Cancer Institute

\section{Source}

National Cancer Institute. Accessory Incompatible. NCI Thesaurus. Code C63036.

An accessory required for the intended purpose of the device appears incompatible with device, thus compromising the intended function of the device. 